\title{
Correction: A characterization of personal care product use among undergraduate female college students in South Carolina, USA
}

Leslie B. Hart • Joanna Walker - Barbara Beckingham • Ally Shelley · Moriah Alten Flagg • Kerry Wischusen • Beth Sundstrom

Published online: 8 April 2020

(C) The Author(s), under exclusive licence to Springer Nature America, Inc. 2020

Correction to: Journal of Exposure Science \& Environmental Epidemiology

https://doi.org/10.1038/s41370-019-0170-1

Total personal care product (PCP) use was misreported in the original paper. The corrected estimates are presented here. The minimum and maximum number of products used weekly was 4 and 26 , respectively. Within $24 \mathrm{~h}$ prior to sampling, the number of products used ranged between 4 and 25. Students reported using $\sim 15$ products in a given week and 13 within $24 \mathrm{~h}$ prior to sampling (weekly mean (s.d.): 14.5 (5.2), median (IQR): 15 (10-19); $24 \mathrm{~h}$ mean (s.d.): 12.3 (4.7), median (IQR): 12.5 (8-15); Table 2). 